\title{
A State of the Art on Supply Planning and Inventory Control under Lead Time Uncertainty
}

\author{
Alexandre DOLGUI ${ }^{1}$, Oussama BEN AMMAR ${ }^{1}$, Faicel HNAIEN ${ }^{2}$, Mohamed Aly O. LOULY \\ ${ }^{1}$ École Nationale Supérieure des Mines, LIMOS, UMR 6158 CNRS, \\ 158 cours Fauriel, 42023 Saint Etienne Cedex 2, France, \\ \{dolgui, obenammar\}@emse.fr \\ 2 Laboratory of Industrial Systems Optimization, University of Technology of Troyes, \\ 12 rue Marie Curie, BP 2060, 10010 Troyes, France, \\ faicel.hnaien@utt.fr \\ ${ }^{3}$ FARCAM, Industrial Engineering Department, \\ College of Engineering, King Saud University, \\ P.O. Box 800, Riyadh 11421, Kingdom of Saudi Arabia, \\ louly@ksu.edu.sa
}

\begin{abstract}
In literature, most papers examine several stochastic demand processes where order lead times are constant. In reality, manufacturing firms use inventory management software, especially MRP, which ignored lead time uncertainty. It is true that in certain special cases, lead time uncertainty has essentially no effect and can be ignored. Nevertheless more often, lead time fluctuations strongly degrade tools performance and cause high production costs, just as demand uncertainty does. Seemingly, uncertainty has been neglected for a long time in favour of studying demand uncertainties. Industry agrees that it is overdue and there is a need to rectify this oversight. Nowadays, this gap in research activity begins to be filled in order to respond to companies having non-deterministic lead-times constraints. This paper reviews some of existing literature of supply planning tools under uncertainty of lead times. The extensive literature review that we compiled consists of citations from 1970 to 2012. A classification scheme for supply planning under uncertainty is defined.
\end{abstract}

Keywords: Production planning, Inventory control, MRP software, Parameterization, Random lead times.

\section{Introduction}

Inventory control in a supply chain is crucial for companies to satisfy their customer demands as well as controlling costs. However, the uncertainty can disrupt the supply and production process (Koh and Saad, 2003). Wazed and al. (2009) have identified the major factors of uncertainty in a real manufacturing environment.

Thousands of papers in the scientific literature proposed several techniques that have been developed to parameterize the Material Requirement Planning (MRP) software under uncertainties. For example, Dolgui and Prodhon (2007) have focused on the development of MRP software for an uncertain environment and have shown that various techniques such as safety stock, safety lead time, and lot-sizing rules can be used to control the supply variability in order to lead the better anticipation of uncertainties.

Whybark and Williams (1976) show how the safety lead time can be used to handle supply uncertainties, such as late delivery. There are other studies in the literature (Molinder 1997,
Guide and Srivasta 2000, Hegedus and Hopp 2001, Koh and Saad 2003, Van Kampen Tim et al. 2010) that have shown similar choices.

In literature, many models exist for a random demand. Indeed, Mula et al. (2006b) have done an excellent review of demand uncertainty and shown that the case of lead time uncertainty was less studied in the past, in spite of their significant importance.

Axsäter (2006) describe two different types of stochastic lead times: stochastic lead times are independent/ or dependent of the lead time demand and independent lead times. The author gave examples of two types of lead times and a numerical comparison. The comparison proves that the inventory level varies much less in case of independent lead times. In Svoronos and Zipkin (1991) there are similar discussions of different types of stochastic lead times: endogenous lead time, dependent of the capacity of system, and exogenous lead time, independent of the capacity of system.

From 1970 to 2012, there have been a lot of research and applications aiming to formalize the uncertainty of lead times in supply chains. 
Table 1 summarizes the paper reviewed in relation to the number of citations from Scopus database (www.scopus.com).

Table 1. Classification scheme for models for supply planning under uncertainty of lead times

\begin{tabular}{|c|c|}
\hline Article & Number of citations \\
\hline Zipkin (1986) & 63 \\
\hline Svoronos and Zipkin (1991) & 69 \\
\hline Song et al. (1999) & 72 \\
\hline Yano (1987 c) & 53 \\
\hline Sphicas et al. (1984) & 14 \\
\hline Lau et al. (1993) & 36 \\
\hline Chiang and Benton. (1994) & 28 \\
\hline Yano (1987 b) & 22 \\
\hline Song and Yano (2000) & 37 \\
\hline Anupindi et al. (1996) & 11 \\
\hline Nasri et al. (1990) & 42 \\
\hline Dolgui and Louly (2002) & 44 \\
\hline Ishii et al. (1981) & 7 \\
\hline Zalkind et al. (1978) & 14 \\
\hline Tang and Grubbström (2003) & 19 \\
\hline Tang and Grubbström (2005) & 21 \\
\hline Alp et al. (2003) & 13 \\
\hline
\end{tabular}

A total of 2082 articles on lead times were reviewed. The majority of papers were found in the following journals: International Journal of Production Economics, European Journal of Operational Research, International Journal of Production Research, Management Science, IIE Transactions, Operations Research, Computers and Industrial Engineering, Production and Operations Management (see Table 2).

The objective of this paper is to: Review the literature, classify the literature based on the modelling approach, and Identify future research directions. We do not describe in detail the models that have been considered.

This paper is organized as follows. In the next section, published research with random lead times and deterministic demand is reviewed and classified. Then, published research with both random lead times and random demand are also reviewed and classified. Finally, in section 4 the conclusions and directions for further research are given. A preliminary version of this paper was presented at IFAC conference MIM 2013 (Ben Ammar et al., 2013).

\section{Random Lead Time and Deterministic Demand}

We will classify the publications by structure of supply systems. Two groups of structures are identified: serial supply and assembly systems.
For these groups, we find also a one level, two level or multi-level structures. For assembly systems, several problems with a one or multiperiod model have been studied in several papers before.

Complexity in assembly system is the dependence between components, i.e., the assembly cannot be carried out if all the necessary components are not available at the right moment. In addition, the complexity of multi-level case is due to the dependence among levels.

\subsection{Serial supply chains}

In the following, the serial supply chain structures with stochastic lead times are reviewed. We presented the case of deterministic demand for one and multilevel serial supply chains. We have started by review the approach details and results for several articles and finally we presented some directions for futures researches.

Table 2. Publications on lead times

\begin{tabular}{|c|c|c|}
\hline Journal & $\begin{array}{c}\text { Number of } \\
\text { articles }\end{array}$ & \% Total \\
\hline Int J Prod Econ & 383 & 18 \\
\hline Euro J Oper Res & 351 & 17 \\
\hline Int J Prod Res & 276 & 13 \\
\hline Manag Sci & 110 & 5 \\
\hline IIE Transac & 98 & 5 \\
\hline Oper Res & 91 & 4 \\
\hline Comp Ind Eng & 89 & 4 \\
\hline Prod Oper Manag & 88 & 4 \\
\hline J Oper Res Soci & 79 & 4 \\
\hline Prod Plan Control & 79 & 4 \\
\hline Int J Adv Manuf Tech & 75 & 4 \\
\hline Comp Oper Res & 70 & 3 \\
\hline Int J Oper Prod Manag & 70 & 3 \\
\hline J Oper Manag & 61 & 3 \\
\hline Naval Res Logist & 60 & 3 \\
\hline Manuf Serv Oper Man & 56 & 3 \\
\hline Int J Syst Sci & 46 & 2 \\
\hline Total & 2082 & 100 \\
\hline
\end{tabular}

The simulation study in Whybark and Williams (1976) suggested that a safety leadtimes may perform better than that of safety stock in a multi-level production-inventory system when the production and replenishment times are stochastic. Nevertheless, Grasso and Taylor (1984) reached another conclusion and prefer safety stocks for both quantity and lead-time uncertainties.

Weeks (1981) developed a one-stage model with tardiness $\left(T_{c}\right)$ and holding costs $\left(H_{c}\right)$ in which the processing time is stochastic and demand is deterministic. The author has proven 
that the problem is equivalent to the standard "Newsboy" problem. Yano (1987a) used an analytic approach to determine optimal planned lead times in serial production systems in which the actual procurement and processing times may be stochastic and demand is deterministic and a lot-for-lot policy is used. The distribution of lead times is supposed stationary in time. The considered cost is the sum of $H_{c}$ and job tardiness costs $\left(T_{c}\right)$. The author presented a general solution procedure for two stage serial systems. Yano (1987a) indicated how the procedure can be extended to $\mathrm{N}$-stage systems. Her experimental results indicate that safety time often should be negative for all but the final production process. Thus from this result the immediate dispatching is usually not optimal. But MRP systems do not use negative planned lead times, and thus the trivial question: why not dispatch everything immediately? Appears this result of negative safety time is obvious because there are only inventory costs at intermediate stage, so the maximum value that can be taken for optimal safety time is zero. This explains why safety lead time can be negative. Consequently, a similar problem is studied by Yano (1987b) but another cost is incurred as rescheduling costs exist at intermediate stage. Then, the objective is to minimize the $H_{c}$, rescheduling arising from tardiness at intermediate stages of production, and late delivery to the customer. The author only studied two and three stage serial systems due to the difficulties of the model. One of the main challenges for the model was to express the objective function in closed form when the number of stage exceeds two stages. The results confirm that immediate dispatching is optimal when rescheduling costs are positive.

To surmount the difficulty to express the closed form for the objective function to the problem presented by Yano (1987b), Elhafsi (2002) developed a recursive scheme that evaluates the objective function efficiently for any number of stages in the production system without recurring to express it in closed form. Due to the convexity of objective function, any classical non-linear optimization algorithm can be used. However, for a large $N$ the computer processing time CPU increases relatively quickly as the number of stages in the system increases. This is due to the polynomial complexity of numerical recursive scheme. To overcome this difficulty, author presents a heuristic based on using only a subset of adequate number of production stages for which the optimal planned lead time can be quickly obtained.

Ramasesh et al. (1991) studied dual sourcing (simultaneous procurement from two suppliers) in the context of the $(s, Q)$ policy and compared it with single sourcing. The authors considered one type of raw material and only the case where the distributions of lead times are uniform or exponential. Sculli and Wu (1981) studied the same problem of one type of raw material ordered from two vendors whose supply lead times are normally distributed but with different parameters. Kelle and Silver (1990) studied the reduction in the safety stock through order splitting when supply lead time follows a Weibull distribution. The following advantages of n-supplier systems compared with a single-supplier are demonstrated: for a given safety stock a higher $S_{l}$ can be achieved, and for a given $S_{l}$ a lower safety stock is needed. However, these studies do not address the problem of determining the optimal order quantity nor order splitting strategy.

Kim et al. (2004) developed an approximate solution to a model with Erlang lead time and deterministic demand. The authors consider the Erlang lead time version of the continuous $(s, Q)$ inventory model with backlogging. The criterion considered was the total expected cost composed of ordering cost, shortage cost and $H_{c}$. Approximate solutions were compared to optimals for the case where prior information on the lead time distribution and for where there is none. The results prove that the approximate solution is as easy as the EOQ's, with an accuracy rate of $99.41 \%$ when prior information on the lead time distribution is available and 97.54$99.09 \%$ when only computer-generated sample information is available.

Silver et al. (2005) dealt with the seasonal lead times for raw materials under constant and fixed demand. The probability distribution of the lead times changes seasonally. The total expected cost of each of the cycles in a year was presented and it is composed of expected setup cost, expected carrying costs and expected shortage costs. The objective consisted in determining the timing of each order and the quantity of each order. The authors gave the analytical expected costs of each of the cycles in year. They also used 
simulation to estimate the true expected total annual costs and proposed two heuristics method for minimizing it: a basic approach and tabu search method.

Arda and Hennet (2006) used the queuing theoretical model for one retailer and several suppliers. There is only one type of product. Lead times are random and follow an exponential distribution while demand for finished product follows a Poisson distribution. The customer orders and the demand is satisfied directly from retailer stock or delayed. The authors use procurement policy $(S-1, S)$. The purpose of detailing is to minimize average costs of storage and rupture. The authors suggested building a procurement policy, defined by an optimal position of the reference stock and a rule to choose the supplier for each order. The numerical results show that the economic benefit to the retailer is to send orders to several suppliers rather than one.

Charharsooghi and Heydari (2010) analyse the performance of a multi-level linear structure. To measure system performance studies, the authors used a simulation to model different combinations of input variables (lead time and supply variances) by indicators: storage, backlog, size, number of stock and the bullwhip effect. These indicators are dependent. Measuring the effect of all independent variable on all dependent variables is possible using the canonical correlation model, which eliminates the impact of intervening variables. According to the results, the authors showed that the effect of the variance of lead time performance is greater than the effect of mean of lead time.

Wazed et al. (2009) have investigated the effects of lead time and machine breakdown in a manufacturing environment. The authors considered the case of an electrical and electronic company located in Singapore. The production is characterized by multiple end items for multi-period and multi-stage dependent demand. A simulation is used to analyse the situations of the production lines. The authors observed that inclusion of common components in the manufacturing system is generally beneficial over the non-commonality environment in uncertain situations. Impacts of machine breakdown on system outcomes are higher than that of the lead time variation. The combination of uncertain factors has more impact on throughput and average production time compared to the individual factor.

Apparently nowhere in literature has supply planning for the serial system under uncertainty of discrete lead times been studied before. Authors have considered continuous lead times where the distribution probability is either known or unknown. However, in industrial world, there are many manufacturing control systems that use discrete lead time data. Consequently it is necessary to investigate this research void and we invite any of our challenge to join us in this endeavour.

\subsection{Assembly systems}

In the following, the assembly systems with stochastic lead times are reviewed. As serial supply chain, we presented the case of deterministic demand for one and multilevel structures.

The additional difficulty for the assembly systems is the dependence between the components needed for assembly operation. This dependence causes a problem to find explicit modelling of the objective function to optimize. We have started by review the approach details and results for several articles and finally we presented some directions for futures researches.

Table 3 summarizes the existing models for assembly systems.

For single item problems, Kaplan (1970) suggested a finite horizon dynamic programming model whose optimal inventory policy turned out to depend on whether the ordering cost is fixed. Liberatore (1979) tried to extend directly the EOQ model so as to treat stochastic lead time, but no closed-form solution was given for optimal order size.

Yano (1987c) considered the problem of twolevel assembly systems with only two types of components at level 2 and one type of components at level 1 . The lead times of the three components are stochastic including Poisson and negative binomial. The problem was to find planned lead times in which minimize the sum of $H_{c}$ and $T_{c}$.

An algorithm was developed which exploits properties of the objective function to find optimal solutions. Computational results indicate that optimal solutions often have negative safety times, there are two situations. 
Table 3. Models for assembly systems

(S-prod: S-prod, multi-component: M-cp, multi-period: M-per, Single-period: S-per.)

\begin{tabular}{|c|c|c|c|c|}
\hline Paper & $\begin{array}{l}\text { Num. of } \\
\text { levels }\end{array}$ & Criteria & System & Comments \\
\hline Yano (1987 c) & 2 & \multirow{5}{*}{$H_{c}, T_{c}$} & \multirow{3}{*}{$\begin{array}{l}\text { S-prod, M-cp, } \\
\text { single-period }\end{array}$} & Nonlinear programming \\
\hline Kumar (1989) & 1 & & & Generic study of inventor control \\
\hline Chu et al. (1993) & 1 & & & iterative algorithm \\
\hline $\begin{array}{l}\text { Dolgui et al. (1995) } \\
\text { Dolgui (2002) }\end{array}$ & 1 & & $\begin{array}{l}\text { Multi-product, M- } \\
\text { cp, M-per }\end{array}$ & $\begin{array}{l}\text { ILP models, simulation, heuristics, optimal } \\
\text { reorder point, optimal assembly lot size. }\end{array}$ \\
\hline Proth et al. (1997) & 1 & & $\begin{array}{c}\text { S-prod, } \mathrm{M-cp,} \mathrm{M-} \\
\text { per }\end{array}$ & Stochastic optimization, Heuristic algorithm \\
\hline Hegedus and Hopp (2001) & 2 & $H_{c}, S_{l}$ & $\begin{array}{l}\text { S-prod, M-cp, } \\
\text { single-period }\end{array}$ & Combinatorial optimization method \\
\hline Dolgui and Louly (2002) & 1 & \multirow{6}{*}{$H_{c}, T_{c}$} & \multirow{2}{*}{$\begin{array}{l}\text { S-prod, } \mathrm{M}-\mathrm{cp}, \mathrm{M}- \\
\text { per }\end{array}$} & $\begin{array}{l}\text { Markov, Newsboy, L4L policy, the lead } \\
\text { times of the different types of components } \\
\text { follow the same distribution probability }\end{array}$ \\
\hline Louly and Dolgui (2002a) & 1 & & & $\begin{array}{l}\text { Markov, Newsboy, all components have } \\
\text { identical properties }\end{array}$ \\
\hline $\begin{array}{c}\text { Tang and Grubbström } \\
\text { (2003) }\end{array}$ & 2 & & S-prod, S-per, 2-cp & Laplace transform procedure \\
\hline Louly and Dolgui (2004) & 1 & & $\begin{array}{l}\text { S-prod, } \mathrm{M-cp}, \mathrm{M}- \\
\text { per }\end{array}$ & $\begin{array}{l}\text { Markov, Newsboy, POQ policy, components } \\
\text { follow the same distribution probability, the } \\
\text { same } H_{c}\end{array}$ \\
\hline Axsäter (2005) & 2,3 & & $\begin{array}{c}\text { S-prod, M-cp, S- } \\
\text { per }\end{array}$ & $\begin{array}{l}\text { Approximate decomposition technique, } \\
\text { continuous distributions }\end{array}$ \\
\hline Louly and Dolgui (2009) & 1 & & \multirow{3}{*}{$\begin{array}{l}\text { S-prod, } \mathrm{M}-\mathrm{cp}, \mathrm{M}- \\
\text { per }\end{array}$} & EOQ policy, Branch and Bound (B\&B) \\
\hline Louly et al. (2008a) & 1 & \multirow{2}{*}{$H_{c}, S_{l}$} & & $\mathrm{~B} \& \mathrm{~B}$ \\
\hline Louly et al. (2008b) & & & & Generaliz. of Louly and Dolgui (2002a) \\
\hline Hnaien et al. (2009) & 2 & \multirow[b]{2}{*}{$H_{c}, T_{c}$} & \multirow{4}{*}{$\begin{array}{l}\text { S-prod, M-cp, S- } \\
\text { per }\end{array}$} & Genetic algorithm (GA), B\&B \\
\hline Chauhan et al. (2009) & 1 & & & $\begin{array}{l}\text { Simulated annealing, exacting solutions, } \\
\text { continuous model }\end{array}$ \\
\hline Hnaien et al. (2010) & 2 & $H_{c}, S_{l}$ & & GA, multi-objective, elitist selection \\
\hline $\begin{array}{l}\text { Fallah-Jamshidi et al. } \\
\text { (2011) }\end{array}$ & 2 & \multirow{2}{*}{$H_{c}, T_{c}$} & & $\begin{array}{l}\text { Hybrid approach, GA of Electromagnetism- } \\
\text { like Mechanism }\end{array}$ \\
\hline Louly and Dolgui (2011) & \multirow[b]{2}{*}{1} & & \multirow[b]{2}{*}{$\begin{array}{l}\text { S-prod, } \mathrm{M-cp}, \mathrm{M}- \\
\text { per }\end{array}$} & \multirow[b]{2}{*}{$\begin{array}{l}\text { POQ Policy, a new generalization of the } \\
\text { Newsboy model }\end{array}$} \\
\hline Louly and Dolgui (2013) & & $\begin{array}{c}\text { Setup } \\
\text { cost, } H_{c} \\
S_{l}\end{array}$ & & \\
\hline Sakiani et al. (2012) & 2 & $H_{c}, S_{l}$ & \multirow{2}{*}{$\begin{array}{l}\text { S-prod, } \mathrm{M}-\mathrm{cp}, \mathrm{S}- \\
\text { per }\end{array}$} & GA, multi-objective, tournament selection \\
\hline $\begin{array}{l}\text { Ben Ammar et al. (2012) } \\
\text { Ben Ammar et al. (2013) }\end{array}$ & $N$ & $H_{c}, T_{c}$ & & Simulation, Mathematical model, GA \\
\hline
\end{tabular}

First, where the component $H_{c}$ and storage cost are both relatively high. Second case, the situation in which one component lead time is much longer than the other. Negative safety times haven't any practical signification. But, in our opinion since that safety time is the difference between planned and expected lead times, then this difference can be negative if the planned lead time is shorter than the expected lead time. Evidently, this result depends also in the values of $H_{c}$ and $T_{c}$.
Kumar (1989) presented a generic study of inventory control in an assembly system of several different components with a singleperiod model where the component procurement lead times are stochastic and the assembly date and quantity are fixed. The problem consists in determining the timing of each component's order so that the total cost, composed of $H_{c}$ and $T_{c}$ of the assembly costs is minimised. Many of her results are based on exact analysis which is only possible to carry 
out for special types of distributions (exponential, uniform, and normal).

Another interesting single-period model of this type was developed in (Chu et al., 1993). Their model deals with a fixed demand for one finished product. To assembly this product several types of components are needed. The lead times of components are random variables. It is necessary to determine the order date for each type of component. The criterion considered is the mathematical expectation of the sum of the $H_{c}$ for the components and the $T_{c}$ for the finished product. The authors prove the convexity of the expected average cost and propose an iterative algorithm to minimize it.

(Dolgui et al., 1995) suggested a model for an assembly planning under constant demand and random component procurement times for the lot for lot policy. Several types of products were considered. For the assembly of each product several types of components are needed. The authors took into account the item $H_{c}$ and $T_{c}$. This model calculates the number of components of each type to be ordered at the beginning of each period and products to be assembled. An approach based on the coupling of an integer linear programming model with a simulation and heuristics was developed. The same problem is studied in (Proth et al., 1997), the components to be ordered and the products to be assembled are selected on the basis of a priority heuristic.

The single-period models do not need to take into account the dependence between stocks of different successive periods for the periodic case. In manufacturing systems, the demand is periodic, therefore this inventory problem is solved at each period and the stocks of the previous periods can be used for the next and so on. However, the mathematical formulation of multi-period problems under lead time uncertainty is more difficult. Orders may cross, that is, they may not be received in the same sequence in which they were placed (He et al. 1998). In certain publications it is assumed that orders do not crossover, and so a single-period problem is solved (Graves et al. 1993).

Hegedus and Hopp (2001) developed a practical method to determine the safety component lead times in an assembly system with uncertainties in the procurement process. Their approach is based on the use of the MRP method with limited production capacity and a time scale discrete and finite. They studied a two-level production system where suppliers have an unlimited capacity. Their lead times are i.i.d random variables and demand and production rates are deterministic. The objective was to minimize the $H_{c}$ subject to $S_{l}$ constraints in a production planning (here, the service is not related to the client, but the percentage of jobs starting time). Their numerical results show that regardless of the level of uncertainty on the supplier lead times, a safety lead time is useful to ensure flexibility. They also looked at the influence of a lot sizing. The combination has effects similar to the introduction of a safety time, but creates the larger $H_{c}$.

Hnaien et al. (2009) and Fallah-Jamshidi et al. (2011) considered a single-period model for two-assembly system. GAs are proposed to determinate the release dates for the components at level two which minimize the total expected cost was minimized which equals to the sum of the inventory $H_{c}$ for components and the $T_{c}$ for the finished product. Considering the applicability of research, current investigation about this area turns to multi-objective optimization, such as (Hnaien et al., 2010) and (Sakiani et al., 2012).

The same problem, but with Inventory Liability Period Contract (ILPC) are studied by Tang et al., (2012). They model the interaction between suppliers and manufacturer as a Stackelberg game which embeds a Nash game about planned lead-times decisions. The centralized system is considered as a benchmark. Authors demonstrate that the optimal planned leadtimes portfolio for a decentralized system can be obtained and that, with optimal lead-times guaranteed, the suppliers penalty cost increases when the Inventory Liability Period (ILP) turns longer. They concluded that ILPC can allocate the inventory cost efficiently among gamers in the supply chain.

In (Ben Ammar et al., 2012), authors studied the same problem; they proposed a simulation model for multi-level assembly systems. It was coupled with a GA. To validate their model, they compared, for two-level assembly systems, their approach with a mathematical model coupled with the same GA. The last approach appears more accurate, efficient and to converge faster than the simulation model coupled with the same GA. However, the simulation model allows the study of multilevel assembly systems. Then, Ben Ammar et 
al. (2013) proposed a mathematical model for multi-level assembly systems which is a generalization of the mathematical model used in Hnaien et al. (2009) and Fallah-Jamshidi et al. (2011).

A multi-period model was proposed in (Gurnani et al. 1996) for assembly systems with two types of components and the lead time probability distributions are limited to two periods. In this model authors supposed that components either arrive in the current period with a given probability $(\beta)$ or in the next period with probability $(1-\beta)$. This two period lead time model gives the optimal quantity of each component to order from each supplier.

Fujiwara and Sedarage (1997) studied a $(Q, r)$ type model for a simple assembly system with stochastic component procurement lead times. Assembly is instantaneous and takes place intermittently in batches but cannot start until all the components are available. The author used the following general assumptions: one finished product and several types of components, constant and known demand rate, and infinite capacity of the assembly system. They considered the inventory $H_{c}$ for the components and the assembled product, shortage cost for the assembled product and setup cost. Fujiwara and Sedarage developed a continuous model for the following $(Q, r)$ ordering policy: when the component inventory depletes to a reorder level $r_{i}$, for component $i$, a batch of size $Q$ of the component $i$ is ordered. The value of $Q$ is the same for all component types. The decisions to be made are the reorder points $r_{i}$ and the lot size $Q$. The obtained nonlinear optimisation problem is decomposed into a family of sub-problems and a solution is obtained numerically.

Bookbinder and Çakanyildirim (1999) considered inventories for $(Q, r)$ models with constant demand and stochastic lead times. The authors developed two probabilistic models. For each model, the convexity of the expected cost is proven and the minimum is obtained. The author's motivation was to help an inventory manager of a JIT system who could invest in decreasing the lead time in a stochastic-order sense. They used $(Q, r)$ approach and gave comparison of their model with the classical $(Q, r)$ model (stochastic demand, fixed lead time) and the EOQ (deterministic demand).
Song et al. (1999) considered the stage due date planning for multistage assembly systems with uncertainties in process times. The authors applied recursively stage by stage the approximate expression for two stage assembly developed by Song et al. (2002). The method is evaluated by comparing it with extensions to existing heuristic methods TWKCP (total work on the critical path) and SLKCP (total work with slack on the critical path) to estimate the product due dates for assemblies (Fry et al. 1989, Smith et al. 1995, Roman and Valle 1996). Simulation examples verify the effectiveness of this method. The results show that the recursive method is better plan, in terms of lead times, costs and $S_{l}$.

Louly and Dolgui (2002) studied the same type of assembly systems as in (Chu et al., 1993) providing some generalizations. Their model is a multi-period model with random lead times and integer decision variables. The finished product demand is periodic and constant (the same for all periods). The criterion considered is the sum of the average $H_{c}$ for the components and the average $T_{c}$ for the finished product. This model gives the optimal values of the safety stocks when the component lead times are i.i.d. random variables and the unit $H_{c}$ are the same for all types of components. This problem was already treated in (Dolgui and Louly, 2002) for the case of Lot-for-Lot policy. A particular case of this model was earlier considered in (Louly and Dolgui, 2004), where all components have identical properties, i.e. the same lead time probability distribution and the same unit $H_{c}$. The Periodic Order Quantity (POQ) policy was modelled and some properties of the objective function were proven. The same problem was solved by a B\&B approach in (Louly et al., 2008a) but for Lot-For-Lot policy with $S_{l}$ constraint.

Tang and Grubbström (2003) considered a two component assembly system problem with stochastic lead times for components and deterministic demand for the finished item. Their study is similar to the work of Yano (1987 c). However, the process time of item at level 1 is assumed to be stochastic, the due date is known and the optimal planned lead time are smaller than the due date. The objective is to minimize the total $T_{c}$ and inventory $H_{c}$. A Laplace transform procedure is used to capture the stochastic properties of lead times. The optimal safety lead time, which is the 
difference between planned and expected lead time is presented.

In Axsäter (2005) a multi-level assembly network was considered with independent stochastic operation times. The objective is to choose starting times for different operations in order to minimize the total expected costs composed of $H_{c}$ of components and delay cost of end items. An approximate decomposition technique that is based on repeat application of the solution of a single-stage problem was suggested. The numerical result for the first example of two stage problems the error is only $1 \%$, i.e., the relative cost increase due to approximation. But, for the second example, three-stage the error is about $10 \%$ and cannot be disregarded.

Houtum et al. (1996) analysed the various structures of multi-levels for the case of assembly and distribution. The objective of the study is to optimize the supply planning policy that minimizes average costs while respecting a high $S_{l}$. The authors have shown that multilevel model is an excellent tool for managing inventory in the different models studied. These models are identified by several structures such as linear system or assembly system.

The authors conducted a comparative study between the Base stock policy (BSC) and Exclusively End-item Buffering (EEB) method. The results show that the costs for BSC may be considerably smaller than for EEB, and thus that for companies it may be wise to use BSC instead of EEB.

Wazed et al. (2009) used WITNESS to simulate, analyse and investigate the uncertainty in lead time. They observe that inclusion of common components in the manufacturing system is generally beneficial over the non-commonality environment, especially in i) uncertain situation, ii) for long procurement lead time of components and iii) when the number of parts increase in the system.

Louly et al. (2008b) used a generalization of discrete Newsboy model proposed in (Louly and Dolgui, 2002) to minimize the average inventory $H_{c}$ for components while maintaining a high $S_{l}$ for the finished product. In (Louly and Dolgui, 2013), POQ policy is considered to determine the optimal values of the order periodicity and planned lead times (parameters of MRP) for all components minimizing the sum of the average $H_{c}$ for the components, average $T_{c}$ for the assembled product and setup cost. A closed form of the criterion is derived. Original lower bounds on the criterion as well as some dominance properties are proposed and proven. This permits the use of a Branch and Cut algorithm based on similar techniques as in (Louly and Dolgui, 2009) and (Louly et al., 2011). The necessary adaptations of this algorithm taking into account that POQ policy is applied are suggested. The obtained algorithm is tested on a set of randomly generated examples.

The supply planning for the multilevel assembly system under uncertainty of discrete or continuous lead times apparently has not been exactly studied before. To our knowledge, there is only the approximate study of (Axsäter, 2005) in the case of continuous lead times only. There is a compelling reason to further study this topic.

\section{Lead Times and Demand Uncertainties}

This section is about simultaneous random demand and random lead times. As mentioned above. There still a lot of work left in this domain. Nevertheless, nowadays such complex systems are beginning to be explored. In most cases, the parameters used are the lot-sizing rules, safety lead time and safety stocks.

Song (1994) considered a simple stochastic dynamic inventory model in which the demands from a compound Poisson process and the lead times are stochastic but exogenous means that the evolution of the lead time is independent of demand and orders. The paper has investigated the effect of lead time uncertainty on optimal inventory control policies and system performance. The author focused on the behaviour of the optimal base stock level in response to stochastically larger or more variable lead times. The author showed that a stochastically larger lead time requires a higher optimal base-stock level. However, a stochastically larger lead time may not necessary result in higher optimal average cost.

Morel et al. (2003) proposed a model using the principle of Holonic Manufacturing System. Vandaele and De Boeck (2003) developed software for high level tuning under input and output uncertainties. The aim is to find a reduced lead time, optimal lot-sizing and the 
utilization levels of the system in order to guarantee a high $S_{l}$. Koh and Saad (2006) presented a business model to diagnose the underlying causes of uncertainties.

Bollopragada and Rao (2006) studied the replenishment planning under supply and demand uncertainties for a single product within a finite horizon with discrete time, and with capacity limits and $S_{l}$ requirements. This approach was be extended by Inderfurth (2009) and Inderfurth and Vogelgesang (2011) to determine appropriate safety stocks and to cope with uncertainties that are caused by demand variability, different types of yield randomness and arbitrary lead times.

A simulation study of MRP systems with a two-level bill-of-materials are proposed by Mohebbi and Choobineh (2005) to analyse the impact of introducing component commonality into an assemble-to-order (ATO) environment when and component procurement lead times are random variables. By using simulated data, their ANOVA results showed that component commonality significantly interacted with existence of demand and supply chain variability, and benefits of component commonality were most pronounced when both uncertainties exist. In the article (Mohebbi et al. (2007), the authors proposed an approach, called the capacity driven procurement system, as an alternative to demand-driven MRP procurement system when the production system is not loaded up to its full capacity and if the system-related performance could be replaced by $S_{l}$ and ease of control.

In the article (Arda and Hennet, 2006), the application of a multi-supplier strategy in a two-level supply chain, with the purpose of evaluating possible savings in $H_{c}$ and $T_{c}$, was analysed. Their approach was modelled as a queuing theoretical model. The authors have proposed a $(S-1, S)$ inventory control policy and have suggested, in the case of a random demand and random delivery delays, that dispatching the orders between several suppliers may be significantly profitable than to direct all the replenishment orders toward a single one.

Zhao and David Simchi-Levi (2006) considered the multi-product and M-cp into ATO systems where the replenishments lead times of the components are stochastic, sequential, and independent of the system state. The demand of each product following independent Poisson processes. The authors characterized the delivery time to satisfy a demand and provide some important system properties for the ATO system with a single end product. For the case of multiple end products, the authors characterized the dependence among the stockout delays of the components and decompose the multi-product ATO system into multiple single product subsystems with each subsystem corresponding to one product.

Song et al. (2010) studied a single-item $(r, q)$ inventory system. The demand is a compound Poisson process. They investigated the behavior of the optimal policy parameters and the long-run average cost of the system in response to stochastically shorter of lessvariable lead times. They showed that although some of the properties of the base-stock system can be extended to this more general model, some cannot.

Feng (2010) examined an integrated decisionmaking process regarding pricing for uncertain demand and sourcing from uncertain supply. Their results indicated that either supply limit and supply uncertainty may induce a significant benefit from dynamic pricing, and the component effect of supply limit and uncertainty can be much more pronounced than the individual effects.

Van Kampen et al. (2010) presented the effect of safety stocks and safety lead times with uncertainty in demand and supply. The simulation experiment confirmed that the benefit of safety stock is its responsiveness whereas safety lead-time increases flexibility. The result proves that the lead time is more effective with supply variability. In other hand safety stock is more effective with uncertainties in demand. For the case with both uncertainties of supply and demand, a safety lead time is more effective than an equivalent level of safety stock. However, the disadvantage of adopting a safety lead time is that it leads to higher inventory levels with a comparable level of safety stock when demand uncertainty is high or the number of stock keeping units.

Altendorfer and Minner (2011) considered a two-stage manufacturing system with random demands processing time, and distributed customer due dates. Under the assumption of a series of $\mathrm{M} / \mathrm{M} / 1$ queuing system, it is shown that the optimal planned lead time values are independent of the distribution of customer required lead time when capacity is predefined. 
This extends the finding of Buzacott and Shanthikumar (1994) and Yano (1987) discussing the planned lead time setting.

Guillaume et al. (2011) proposed a method for computing gross requirements taking into account the uncertainty on the demand and on the lead times, within a decision support approach. This method gives a set of plans represented in a graph. In this graph, each level denotes a period and each path defines a scenario. A possibility distribution, representing the possible quantities to process during a period, is attached to each node. Each arc is valued by the possibility level that the link exists. The method can be used to determinate robust release policies. For critical products, it takes into account the levels of possibility/necessity to require the quantities to produce, and helps the decision maker to choose iteratively theses quantities to produce.

Arts et al. (2013) used Markov chains to study the inventory control of a single product in one location with two supply sources facing stochastic demand. To find the optimal orderup-to level, the authors provided a proof that separates the optimization of the dual-index policy in two one-dimensional problems. The model was then generalized to accommodate stochastic lead times.

\section{Conclusions and Further Research}

This paper has presented an exhaustive literature survey about models for supply planning under uncertainty of lead times. The safety lead times, safety stocks and the modelling approach were the taxonomy criteria used.

The analytical modelling approach was the most frequently encountered. Most of the analytical models assumed a simple structure of the supply chain (one level) and one period planning. For more complex processes, with multilevel supply chain and more than one period, the analytical approach is replaced by methodologies based on simulation. Although a lot of work use simulation approaches to model uncertainty, very few studies exist on the comparative evaluation of the advantages and inconveniences of different simulation languages.

Although an extensive literature on models for supply planning under uncertainty of lead times was reviewed, needs for further research have been identified: (1) investigation of new approaches to contain additional sources and types of uncertainty, such as transport times, quality uncertainty, failure of production system, etc. (2) development of new models that contain additional resources and types of uncertainty, such as both supply lead times and finished product demand uncertainty, (3) development of a new modelling for the more complex problem of multilevel assembly system where there is the additional complexity of the dependence between inventory of components at each level and the dependence between levels.

\section{REFERENCES}

1. ALP, O., N. K. ERKIP, R. GÜLLÜ, Optimal Lot-sizing/Vehicle-dispatching Policies under Stochastic Lead Times and Stepwise Fixed Costs. Operations Research, vol. 51(1), 2003, pp. 160-166.

2. ALTENDORFER, K., S. MINNER, Simultaneous Optimization of Capacity and Planned Lead Time in a Two-stage Production System with Different Customer Due Dates. European Journal of OR, vol. 213, 2011, pp. 134-146.

3. ANUPINDI, R., MORTON, T. E., PENTICO, D., The Non-stationary Stochastic Lead-time Inventory Problem: Near-myopic Bounds, Heuristics, and Testing. Management Science, vol. 42(1), 1996, pp. 124-129.

4. ARDA, Y., J. C. HENNET, Inventory Control in a Multi-supplier System. International Journal of Production Economics, vol. 104(2), 2006, pp. 249-259.

5. ARTS, J., G. P. KIESMÜLLER, Analysis of a Two-echelon Inventory System with Two Supply Modes. European J. of OR., vol. 225, 2013, pp. 263-272.

6. AXSÄTER, S., Planning Order Releases for an Assembly System with Random Operation Times. OR. Spectrum, vol. 27, 2005, pp. 459-470.

7. AXSÄTER, S., Inventory Control. Second Edition. Springer, 2006.

8. BEN AMMAR, O., H. MARIAN, A. DOLGUI, Configuration d'un système d'assemblage multi-niveau sous incertitudes des délais 
d'approvisionnement. In : Actes de la conférence internationale Modélisation, Optimisation et Simulation (MOSIM'12), Bordeaux, France, 2012.

9. BEN AMMAR, O., MARIAN H., WU D., and DOLGUI A. A General Mathematical Model for Supply Planning of Multi-level Assembly Systems with Stochastic Lead Times, Invited keynote paper for a special session, Proceedings of the IFAC Conference on Manufacturing Modelling, Management and Control (MIM'2013), St Petersburg, Russia, June 19-21, 2013, N. Bakhtadze, A. Dolgui, V. Lototsky (Eds.), Elsevier Science, 2013, IFAC-PapersOnline.net.

10. BOOKBINDER, J. H., M, CAKANYILDIRIM, Random Lead Times and Expected Orders in $(Q, r)$ Inventory Systems. European J. of OR, vol. 115, 1999, pp. 300-313.

11. BUZACOTT, J. A., J. G. SHANTHIKUMAR, Safety Stock versus Safety Time in MRP controlled Production Systems. Management Science, vol. 40(12), 1994, pp. 1678-1689.

12. CHAUHAN, S., A. DOLGUI, J.-M. PROTH, A Continuous Model for Supply Planning of Assembly Systems with Stochastic Component Procurement Times. International Journal of Production Economics, vol. 120, 2009, pp. 411-417.

13. CHIANG, C., W. C. BENTON, sole Sourcing versus Dual Sourcing under Stochastic Demands and Lead Times. Naval Research Logistics, vol. 41(5), 1994, pp. 609-624.

14. CHU, C., J. M. PROTH, X. XIE, Supply Management in Assembly Systems. Naval Research Logistics, vol. 40, 1993, pp. 933-949.

15. DOLGUI, A., M. C. PORTMANN, J. M. PROTH, Planification de systèmes d'assemblage avec approvisionnement aléatoire en composants. J. of Decision Systems, vol. 4(4), 1995, pp. 255-279.

16. DOLGUI, A., M. C. PORTMANN, J. M. PROTH, A Control Model of the Assembly Manufacturing. In: Dolezal, J., Fidler, J. (Eds.), System Model. and Optim. Proc. 17th IFIP TC7 Conf. Chapman and Hall, London, 1996, pp. 519-526.
17. DOLGUI, A., A Model of Joint Control of Reserves in Automatic Control Systems of Production. Automation and Remote Control, vol. 62, 2001, pp. 2020-2026.

18. DOLGUI, A. M. A. LOULY, A Model for Supply Planning under Lead Time Uncertainty. Intl. Journal of Production Economics, vol. 78, 2002, pp. 145-152.

19. DOLGUI, A., M. A. LOULY, C. PRODHON, A Survey on Supply Planning under Uncertainties in MRP Environments. Proc. 16th IFAC World Congress, Prague, Czech Republic, 2005.

20. DOLGUI, A., M. LOULY, A Model for Supply Planning under Lead Time Uncertainty. Intl. Journal of Production Economics, vol. 78, 2002, pp. 145-152.

21. DOLGUI, A., C. PRODHON, Supply Planning under Uncertainties in MRP Environments: A State of the Art. Ann. Rev. in Control, vol. 31, 2007, pp. 269-279.

22. BEN AMMAR, O., A. DOLGUI, F. HNAIEN, M. A. LOULY, Supply Planning and Inventory Control under Lead Time Uncertainty: A Review, Invited keynote paper for a special session, Proc. IFAC Conf. on Manufacturing Modelling, Management and Control (MIM'2013), St Petersburg, Russia, June 19-21, 2013, N. Bakhtadze, A. Dolgui, V. Lototsky (Eds.), Elsevier Science, 2013, IFAC-PapersOnline.net.

23. ELHAFSI, M., Optimal Leadtimes Planning in Serial Production Systems with Earliness and Tardiness Costs. IIE Transactions, vol. 34, 2002, pp. 233-243.

24. FALLAH-JAMSHIDI, S., N. KARIMI, M. ZANDIEH, A Hybrid Multi-objective GA for Planning Order Release Date in Twolevel Assembly System with Random Lead Times. Expert Systems with Applications, vol. 38(11), 2011, pp. 13549-13554.

25. FENG, Q., Integrating Dynamic Pricing and Replenishment Decisions under Supply Capacity Uncertainty. Man. Science, vol. 56(12), 2010, pp. 2154-2172.

26. FRY, T. D., M. D. OLIFF, E. D. MINOR, G. K. LEONG, The Effect of Product Structure and Sequencing Rule on Assembly Shop Performance. Intl. J. of Prod. Research, vol. 27, 1989, pp.671-686. 
27. FUJIWARA, O., D. SEDARAGE, An Optimal $(Q, r)$ Policy for a Multipart Assembly System under Stochastic Part Procurement Lead Times. European J. of OR, vol. 100, 1997, pp. 550-556.

28. GRAVES, S. C., Handbooks in Operations Research and Management Science. vol. 4: Logistics of Production and Inventory, Amsterdam, Holland, 1993.

29. GUIDE, V. D. R., R. SRIVASTAVA, A Review of Techniques for Buffering against Uncertainty with MRP Systems. Intl. J. of Production Planning and Control, vol. 11, 2000, pp. 223-233.

30. GUILlaUME, R., C. THIERRY, B. GRABOT, MRP with Imprecise Demand and Uncertain Lead Time. Adv. in Intel. Sys. Res., vol. 1(1), 2011, pp. 673-679.

31. GURNANI, H., R. AKELLA, J. LEHOCZKY, Optimal Order Policies in Assembly Systems with Random Demand and Random Supplier Delivery. IIE Trans., vol. 28, 1996, pp. 865-878.

32. HE, X., S. H. XU, J. K. ORD, J. C. HAYYA, An Inventory Model with Order Crossover. Operations Research, vol. 46, 1998, pp. 112-119.

33. HEGEDUS, M., W. HOPP, Setting Procurement Safety Lead-times for Assembly Systems. Intl. J. of Prod. Res., vol. 39, no. 15, 2001, pp. 3459-3478.

34. HNAIEN, F., X. DELORME, A. DOLGUI, GA for Supply Planning in Two-level Assembly Systems with Random Lead Times. Eng. App. of Artificial Intelligence, vol. 22, 2009, pp. 906-915.

35. HNAIEN, F., X. DELORME, A. DOLGUI, Multi-objective Optimization for Inventory Control in Two-level Assembly Systems under Uncertainty of Lead Times. Computers \& Operations Research, vol. 37, 2010, pp. 1835-1843.

36. INDERFURTH, K., How to Protect Against Demand and Yield Risks in MRP Systems. Intl. J. of Prod. Ec., vol. 121, no. 2, 2009, pp. 474- 481.

37. INDERFURTH, K., S. VOGELGESANG, Concepts for Safety Stock Determination under stochastic demand and Different Types of Random Production Yield.
European J. of Operational Research, vol. 224, 2013, pp. 293-301.

38. ISHII, H., T. NOSE, S. SHIODE, T. NISHIDA, Perishable Inventory Management Subject to Stochastic Leadtime. European J. of OR, vol. 8(1), 1981, pp. 76-85.

39. KAPLAN, R. S., A Dynamic Inventory Model with Stochastic Lead Times. Man. Science, vol. 16, 1970, pp. 491-507.

40. KELLE, P., E. A. SILVER, Safety Stock Reduction by Order Splitting. Naval Res. Logistics, vol. 37, 1990, pp. 725-743.

41. KIM, J. G., D. SUN, X. J. HE, J. C. HAYYA, The $(s, Q)$ Inventory Model with Erlang Lead Time and Deterministic Demand. Naval Research Logistics, vol. 51, 2004, pp. 906-923.

42. KOH, S., S. SAAD, MRP-controlled Manufacturing Environment Disturbed by Uncertainty. Robotics and ComputerIntegrated Manufacturing, vol. 12(1-2), 2003, pp. 157-171.

43. KUMAR, A., Component Inventory Cost in an Assembly Problem with Uncertain Supplier Lead-Times. IIE Transactions, vol. 21, no. 2, 1989, pp. 112-121.

44. LAU, H., L. ZHAO, Optimal Ordering Policies with Two Suppliers when Lead Times and Demands are All Stochastic. European Journal of Operational Research, vol. 68, no. 1, 1993, pp. 120-133.

45. LIBERATORE, M. J., The EOQ Model under Stochastic Lead Times. Operations Research, vol. 27, 1979, pp. 391-396.

46. MOHEBBI, E., F. CHOOBINEH, The Impact of Component Commonality in an Assemble-to-order Environment under Supply and Demand Uncertainty. Omega - The Intl. J. of Management Science, vol. 33, 2005, pp. 472-482.

47. MOHEBBI, E., F. CHOOBINEH, A. PATTANAYAK, Capacity-driven versus Demand-driven Material Procurement Systems. Intl. J. of Production Economics, 107, 2007, pp. 451-466.

48. MOLINDER, A., Joint Optimization of Lot-sizes, Safety Stocks and Safety Lead Times in an MRP System. Intl. J. of Prod. Research, 35, 1997, pp. 983-994. 
49. MULA, J., R. POLER, J. GARCIA-SABATER, F. LARIO, Models for Production Planning under Uncertainty: A Review. International Journal of Production Economics, 103, no. 1, 2006, pp. 271-285.

50. NASRI, F., J. F. AFFISCO, M. J. PAKNEJAD, Setup Cost Reduction in an Inventory Model with Finite-range Stochastic Lead Times. Intl. J. of Prod. Res., vol. 28(1), 1990, pp. 199-212.

51. LOULY, M. A., A. DOLGUI, Generalized Newsboy Model to Compute the Optimal Planned Lead Times in Assembly Systems. Intl. J. of Production Research, 40, 2002a, pp. 4401-4414.

52. LOULY, M., A. DOLGUI, Supply Planning Optimization under Uncertainties. Intl. Journal of Agile Manufacturing, 5, no. 1, 2002b, pp. 17-26.

53. LOULY, M. A., A. DOLGUI, The MPS Parameterization under Lead Time Uncertainty. Intl. Journal of Production Economics, 90, 2004, pp. 369-376.

54. LOULY, M., A. DOLGUI, F. HNAIEN, Supply Planning for Single-level Assembly System with Stochastic Component Delivery Times and Service Level Constraint. Intl. J. of Prod. Ec., 115, no. 1, 2008a, pp. 236-247.

55. LOULY, M., A. DOLGUI, F. HNAIEN, Optimal Supply Planning in MRP Environments for Assembly Systems with Random Component Procurement Times. Intl. J. of Prod. Research, vol. 46, no. 19, 2008b, pp. 5441-5467.

56. LOULY, M., A. DOLGUI, Calculating Safety Stocks for Assembly Systems with Random Component Procurement Lead Times: A Branch and Bound Algorithm. European J. of Operational Research, vol. 199, no. 3, 2009, pp. 723-731.

57. LOULY, M. A., A. DOLGUI, Optimal Time Phasing and Periodicity for MRP with POQ Policy. Intl. J. of Prod. Economics, 131, no. 1, 2011, pp. 76-86.

58. LOULY, M. A., A. DOLGUI, Optimal MRP Parameters for a Single Item Inventory with Random Replenishment Lead Time, POQ Policy and Service Level Constraint. Intl. J. of Prod. Economics, vol. 143, 2013, pp. 35-40.
59. PROTH, J. M., G. MAUROY, Y. WARDI, C. CHU, X. XIE, Supply Management for Cost Minimization in Assembly Systems with Random Components Yield Times. J. of Intel. Man., 8, 1997, pp. 385-403.

60. RAMASESH, R. V., J. K. ORD, J. C. HAYYA, A. PAN, Sole versus Dual Sourcing in Stochastic Lead-time $(s, Q)$ Inventory Models. Management Science, vol. 37, no. 4, 1991, pp. 428-443.

61. ROMAN, D. B., A. G. VALLE, Dynamic Assignment of Due Dates in an Assembly Shop based in Simulation. Intl. J. of Prod. Research, vol. 34, 1996, pp. 1539-1554.

62. SAKIANI, R., S. F. GHOMI, M. ZANDIEH, Multi-objective Supply Planning for Two-level Assembly Systems with Stochastic Lead Times. Computers \& Operations Research, vol. 39, no. 7, 2012, pp. 1325-1332.

63. SCULLI, D., S. Y. WU, Stock Control with Two Suppliers and Normal Lead Time. J. of Operational Research Society, vol. 32, no. 11, 1981, pp. 1003-1009.

64. SILVER, E. A., Inventory Control of Raw Materials under Stochastic and Seasonal Lead Times. Intl. J. of Prod. Res., vol. 40, no. 17, 2005, pp. 4401-4414.

65. SMITH, C. H., E. D. MINOR, H. J. WEN, Regression-based Due Date Assignment Rules for Improved Assembly Shop Performance. Intl. J. of Prod. Research, vol. 33, 1995, pp. 2375-2385.

66. SONG, J.-S., S. H. XU, B. LIU, Orderfulfilment Performance Measures in an Assemble-to-order System with Stochastic Leadtimes. Operations Research, vol. 47, no. 1, 1999, pp. 131-149.

67. SONG, D. P., C. HICKS, C. F. EARL, Due Date Planning in Manufacturing Systems with Complex Product Structure and Uncertain Processing Times. Intl. J. of Prod. Economics, vol. 76, no. 3, 2002, pp. 243-256.

68. SONG, D. P., C. HICKS, C. F. EARL, Stage Due Date Planning for Multistage Assembly Systems. Intl. J. of Prod. Res., vol. 39, no. 9, 2001, pp. 1943-1954.

69. SONG, J. S., The Effect of Leadtime Uncertainty in a Simple Stochastic 
Inventory Model. Management Science, vol. 40, no. 5, 1994, pp. 603-613.

70. SONG, J. S., C. A. YANO, P. LERSSRISURIYA, Contract Assembly: Dealing with Combined Supply Lead Time and Demand Quantity Uncertainty. Manufacturing and Service Operations Management, vol. 2(3), 2000, pp. 287-296.

71. SONG, J. S., H. ZHANG, Y. HOU, M. WANG, The Effect of Lead Time and Demand Uncertainties in $(r, q)$ Inventory Systems. Operations Research, 58, no. 1, 2010, pp. 68-80.

72. SPHICAS, G. P., F. NASRI, Inventory Model with Finite-range Stochastic Lead Times. Naval Research Logistics, vol. 31, no. 4, 1984, pp. 609-616.

73. SVORONOS, A., P. ZIPKIN, Evaluation of One-for-one Replenishment Policies for Multiechelon Inventory Systems. Management Sc., vol. 37, 1991, pp. 68-83.

74. TANG, O., R. W. GRUBBSTRÖM, The Detailed Coordination Problem in a Two-level Assembly System with Stochastic Lead Times. Intl. J. Prod. Economics, vol. 81-82, 2003, pp. 415-429.

75. TANG, O., R. W. GRUBBSTRÖM, Considering Stochastic Lead Times in a Manufacturing/Remanufacturing System with Deterministic Demands and Returns. Intl. J. of Prod. Economics, vol. 93-94, 2005, pp. 285-300.

76. TANG, Y., S.-H. MA, Q.-C. ZHOU, Optimal Planned Lead-times in Twolevel Assembly System with Inventory Liability Period Contract. In Proceedings of the 2012 Intl. Conference on Management Science and Engineering (ICMSE), 2012, pp. 439-444.

77. VANDAELE, N., L. De BOECK, Advanced Resource Planning. Robotics and Computer Integrated Manufacturing, 19, 2003, pp. 211-218.

78. Van KAMPEN T. J., D. P. Van DONK, D.J. Van Der ZEE, Safety Stock or Safety
Lead Time: Coping with Unreliability in Demand and Supply. Intl. J. of Prod. Res., vol. 48, no. 23-24, 2010, pp. 7463-7481.

79. WAZED, M., A. SHAMSUDDIN, N. YUSOFF, Uncertainty Factors in Real Manufacturing Environment. Australian J. of Basic and Applied Sciences, vol. 3, no. 2, 2009, pp. 342-351.

80. WEEKS, J. K., Optimizing Planned Lead Times and Delivery Dates. Proceedings of the 21st annual Conference of American Prod. and Inventory Control Society, 1981, pp. 177-188.

81. WHYBARK, D. C., J. G. WILLIAMS, Material Requirements Planning Under Uncertainty. Decision Science, vol. 7, 1976, pp. 595-606.

82. YANO, C. A., Setting Planned Leadtimes in Serial Production Systems with Tardiness Costs. Management Science, vol. 33, no. 1, 1987a, pp. 95-106.

83. YANO, C. A., Planned Lead-times for Serial Production Systems. IIE Trans., vol. 19, no. 3, 1987b, pp. 300-307.

84. YANO, C. A., Stochastic Lead-times in Two-level Assembly Systems. IIE Trans., vol. 19, no. 4, 1987c, pp. 95-106.

85. ZALKIND, D., Order-level Inventory Systems with Independent Stochastic Lead-times. Management Science, vol. 24, no. 13, 1978, pp. 1384-1392.

86. ZHAO, Y., D. SIMCHI-LEVI, Performance Analysis and Evaluation of Assemble-to-order Systems with Stochastic Sequential Lead Times. Operation Research, vol. 54(4), 2006, pp. 706-724.

87. ZIPKIN, P., Foundation of Inventory Management, McGraw-Hill, USA, 2000.

88. ZIPKIN, P., Stochastic Lead-times in Continuous-time Inventory Models. Naval Research Logistics, vol. 33, 1986, pp. 763-774. 